\title{
USE OF POSITIVE PRESSURE IN THE BARIATRIC SURGERY AND EFFECTS ON PULMONARY FUNCTION AND PREVALENCE OF ATELECTASIS: RANDOMIZED AND BLINDED CLINICAL TRIAL
}

\author{
Uso da pressão positiva em cirurgia bariátrica e efeitos sobre a função pulmonar e prevalência de atelectasias: estudo \\ randomizado e cego
}

Letícia BALTIERI, Laisa Antonela SANTOS, Irineu RASERA-JUNIOR, Maria Imaculada Lima MONTEBELO, Eli Maria PAZZANOTTO-FORTI

From the Universidade Metodista de Piracicaba (Methodist University of Piracicaba), Piracicaba, SP, Brazil.

HEADINGS - Obesity, morbid. Bariatric surgery. Pulmonary atelectasis. Continuous positive airway pressure. Physical therapy specialty.
ABSTRACT - Background: In surgical procedures, obesity is a risk factor for the onset of intra and postoperative respiratory complications. Aim: Determine what moment of application of positive pressure brings better benefits on lung function, incidence of atelectasis and diaphragmatic excursion, in the preoperative, intraoperative or immediate postoperative period. Method: Randomized, controlled, blinded study, conducted in a hospital and included subjects with BMI between 40 and $55 \mathrm{~kg} / \mathrm{m}^{2}, 25$ and 55 years, underwent bariatric surgery by laparotomy. They were underwent preoperative and postoperative evaluations. They were allocated into four different groups: 1) Gpre: treated with positive pressure in the BiPAP mode (Bi-Level Positive Airway Pressure) before surgery for one hour; 2) Gpos: BIPAP after surgery for one hour; 3) Gintra: PEEP (Positive End Expiratory Pressure) at $10 \mathrm{cmH}_{2} \mathrm{O}$ during the surgery; 4) Gcontrol: only conventional respiratory physiotherapy. The evaluation consisted of anthropometric data, pulmonary function tests and chest radiography. Results: Were allocated 40 patients, 10 in each group. There were significant differences for the expiratory reserve volume and percentage of the predicted expiratory reserve volume, in which the groups that received treatment showed a smaller loss in expiratory reserve volume from the preoperative to postoperative stages. The postoperative radiographic analysis showed a $25 \%$ prevalence of atelectasis for Gcontrol, $11.1 \%$ for Gintra, 10\% for Gpre, and 0\% for Gpos. There was no significant difference in diaphragmatic mobility amongst the groups. Conclusion: The optimal time of application of positive pressure is in the immediate postoperative period, immediately after extubation, because it reduces the incidence of atelectasis and there is reduction of loss of expiratory reserve volume.

\section{Correspondence:}

Eli Maria Pazzianotto-Forti

E-mail: empforti@unimep.br

Financial source: none

Conflicts of interest: none

Received for publication: 20/03/2014

Accepted for publication: 13/06/2014

Registration of clinical trial: NCT01786681

DESCRTORES - Obesidade mórbida. Cirurgia bariátrica. Atelectasia pulmonar. Pressão positiva contínua nas vias aéreas. Fisioterapia.
RESUMO - Racional: Em procedimentos cirúrgicos, a obesidade é fator de risco para o surgimento de complicações intra e pós-operatórias. Objetivo: Determinar qual o momento em que a aplicação de pressão positiva traz melhores benefícios na função pulmonar, prevalência de atelectasias e mobilidade diafragmática, no pré, no intra ou no pós-operatório. Método: Estudo randomizado, controlado e cego, conduzido em hospital e incluídos pacientes com IMC entre 40 e $55 \mathrm{~kg} / \mathrm{m}^{2}$, 25 e 55 anos, submetidos à cirurgia bariátrica por laparotomia. Foram avaliados no pré e no pósoperatório. Foram alocados em quatro grupos: 1) Gpré: tratados com pressão positiva no modo BiPAP (Bi-Level Positive Airway Pressure) antes da operação por uma hora; 2) Gpós: tratados com BIPAP após a operação, por uma hora; 3) Gintra: aplicação de PEEP (Positive End Expiratory Pressure) de $10 \mathrm{cmH}_{2} \mathrm{O}$ durante a cirurgia; 4) Gcontrole: apenas fisioterapia convencional. A avaliação consistiu de coleta de dados antropométricos, teste de função pulmonar e radiografia de tórax. Resultados: Foram alocados 40 pacientes, $10 \mathrm{em}$ cada grupo. Houve diferença significativa para o volume de reserva expiratório e respectiva porcentagem do predito, no qual os grupos que receberam tratamento adicional apresentaram menor perda do volume de reserva expiratório do pré ao pós-operatório. A radiografia de tórax pós-operatória mostrou $25 \%$ de prevalência de atelectasias para o Gcontrole, 11,1\% para o Gintra, 10\% para o Gpré, e 0\% para o Gpós. Não houve diferença significativa na mobilidade diafragmática entre os grupos. Conclusão: O momento ideal de aplicação da pressão positiva é no pós-operatório imediato, pois reduz a prevalência de atelectasias e há menor perda do volume de reserva expiratório.

I n surgical procedures, especially in access by laparotomy, obesity is a risk factor for the onset of intra and postoperative respiratory complications when compared to non-obese individuals, especially in surgery of the upper abdomen (Rose et al., 1994; Chung et al., 1999). Postoperatively there may be decreased lung volumes, respiratory muscle dysfunction (Barbalho-Moulim et al., 2011), appearance of atelectasis due to a reduction in the functional residual capacity and increased shunt in the intraoperative stage. These changes are related to the need for a general anesthetic (Lundquist et al., 1995; Perilli et al., 2000; Coussa et al., 2004). Furthermore, the surgical handling can lead to a reflex inhibition of the phrenic nerve and diaphragmatic paresis, aggravating the incidence of atelectasis (Levi et al., 2003). It appears within minutes after the induction of anesthesia in 
$85-90 \%$ of patients, and the adverse effects persist during the postoperative stage, affecting the patient's recovery (Lundquist et al., 1995; Eichenberger et al., 2002; Duggan et al., 2005).

Several studies have reported the benefits of respiratory physiotherapy in the pre and postoperative stages of these patients (Barbalho-Moulim et al., 2009) thus preventing the pulmonary complications related to bariatric surgery and other abdominal surgeries. The physical therapy resources used include positive pressure, which promotes a rapid recovery of lung function and prevents atelectasis (Ricksten et al., 1986; El-Solh et al. 2006; Lawrence et al., 2006; Gaszynski et al., 2007; Souza et al., 2009).

There are studies in the literature that demonstrate the benefits of applying positive pressure at various isolated times from hospitalization for bariatric surgery. However, there are no studies that compare the best time of intervention with positive pressure therapy for these patients.

Therefore the objective of this study was to determine what moment of application of positive pressure brings better benefits on lung function, incidence of atelectasis and diaphragmatic excursion, in the preoperative, intraoperative or immediate postoperative period.

\section{METHODS}

This was a randomized, controlled, blinded clinical trial approved by the Ethics in Research Committee of the Methodist University of Piracicaba under protocol $n^{\circ} 54 / 11$.

Individuals with body mass index (BMI) between 40 and $55 \mathrm{~kg} / \mathrm{m}^{2}$, aged between 25 and 55 years, were submitted to Roux-en-Y type gastric bypass by laparotomy were included. Patients showing abnormal preoperative pulmonary function test, with postoperative hemodynamic instability, a hospital stay longer than three days or the presence of postoperative complications were excluded.

The initial screening of the volunteers was carried out at the Bariatric Clinic by examining the patient's medical records for possible inclusion in the study and, subsequently, conducted at the hospital.

The calculation of sample size was based on a pilot study, considering the difference of the values of the expiratory reserve volume (ERV) obtained between the pre and postoperative. Was used a least significant difference (0.18) and standard error (0.11) and the ANOVA test, adopting a statistical power of $80 \%$ and an alpha of 0.05. Thus, was determined a 10 per group volunteers. Processing the sample size calculation was performed using the software BioEstat version 5.3.

After verifying patient eligibility, block randomization was carried out using the Microsoft Excel $2007{ }^{\circledR}$ program, for allocation into the groups. The volunteers were divided into four different groups: 1) Gpre: subjects treated with positive pressure in the BiPAP mode ( $\mathrm{Bi}$-Level Positive Airway Pressure) for one hour before surgery; 2) Gpos: individuals treated with positive pressure (BiPAP) for one hour after surgery; 3) Gintra: individuals treated with 10 $\mathrm{CmH}_{2} \mathrm{O}$ of positive end expiratory pressure (PEEP) during the surgical procedure; 4) Gcontrol: individuals treated with conventional physiotherapy according to the routine service of physiotherapy of the hospital, including the techniques of pulmonary re-expansion, breathing exercises (deep breaths or fractional), the use of incentive spirometry (Respiron ${ }^{\circledR}$ ) and assisted ambulation.

The BiPAP Synchrony II - Respironics ${ }^{\circledR}$ equipment was used for the groups treated with non-invasive positive pressure (Gpre and Gpos). The inspiratory positive airway pressure was initially set at $12 \mathrm{cmH}_{2} \mathrm{O}$, and adjusted according to the individual's tolerance, while maintaining a respiratory rate below 30 and a tidal volume of about 8 to $10 \mathrm{ml} / \mathrm{kg}$, using the ideal weight. The expiratory positive airway pressure was set at $8 \mathrm{cmH}_{2} \mathrm{O}$.

All the patients underwent bariatric surgery with the same surgical team, under general anesthesia and standard mechanic ventilation. The preoperative evaluation (same day as surgery) and postoperative (second day after surgery) of all the volunteers was carried out by the same blinded investigator.

Before starting the postoperative evaluation, the degree of pain was assessed using a Visual Analogue Scale with a score from 0 to 10 (Downie et al., 1978; Scott et al., 1976). When the pain was $\leq 4$, the evaluation was started normally, but when the pain was $>4$, an analgesic (dipyrone) was given, and the pain classified again after 30 minutes (Gaszynski et al., 2007).

\section{Outcome measures}

Anthropometric data

The collection of body mass was performed using a digital scale (Filizola ${ }^{\circledR}$ Brazil) duly calibrated, with a maximum capacity of $300 \mathrm{~kg}$ and a resolution of $100 \mathrm{~g}$, it is possible to calculate the BMI, ideal body weight (Metropolitan Life Foundation 1983) and body mass in excess. Height was verified by a wall stadiometer.

\section{Pulmonary function test}

Spirometry was carried out according to the guidelines of the American Thoracic Society and European Respiratory Society (2005) using the equipment MicroQuark PonyFC (Cosmed ${ }^{\circledR}$, Roma, Itália). The predicted values were calculated using the equation proposed by Pereira et al. (1992 e 2002).

\section{Chest radiography}

The chest X-ray was made using two radiographic exposures. The first was taken at the end of a maximal inspiration, and the second in profound exhalation without changing the position of the film or the patient.

The radiological report on the inspiration radiography, issued by the hospital radiologist, was used to analyze the presence of atelectasis. The diaphragmatic mobility was analyzed by superimposing the two radiological films, and calculating the distance between the highest point of the diaphragm in expiration and the highest point of the dome on bilateral inspiration.

\section{Data analysis}

The data analysis calculation was performed using the software SPSS 17.0. For intragroup analysis normality was verified using the Shapiro-Wilk and variables with normality was applied Student's t test for related data, and the variables that was not normal was applied the Wilcoxon test. For comparison between groups, if the assumptions for normality and homoscedasticity were not satisfied using the Shapiro-Wilk and Levene tests, the Kruskal-Wallis test was applied with a post-hoc Dunn. A significance level of $5 \%$ was adopted.

\section{RESULTS}

During the 20 week study period, 271 patients underwent surgery, and of these, 228 were excluded according to the previously established criteria. Thus 43 patients were studied, and of these, three were excluded, leaving 40 patients, 10 in each group, as shown in the flowchart (Figure 1). 


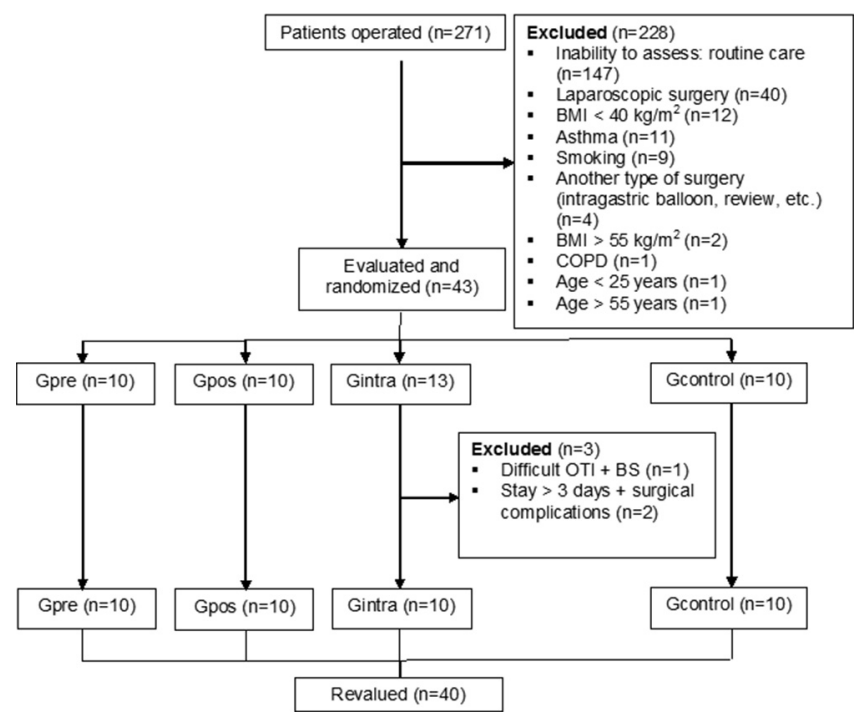

$\mathrm{BMI}=$ body mass index; $\mathrm{COPD}=$ chronic obstructive pulmonary disease $\mathrm{OTI}=$ orotracheal intubation; $\mathrm{BS}=$ bronchospasm

FIGURE 1 - Flowchart of patients included

There were no statistical differences in the distribution of the voluntary groups (Table 1 ).

TABLE 1 - Means and standard deviations for the ages and anthropometric characteristics of the 40 volunteers, distributed in the four groups

\begin{tabular}{|c|c|c|c|c|}
\hline & Gpre & Gpos & Gintra & Gcontrol \\
\hline Gender (F/M) & $8 / 2$ & $8 / 2$ & $9 / 1$ & $8 / 2$ \\
\hline Age (years) & $42 \pm 11.2$ & $38.8 \pm 9.6$ & $37.3 \pm 11.4$ & $42.6 \pm 11.6$ \\
\hline Body mass (kg) & $120.9 \pm 17.0$ & $125.2 \pm 22$ & $119.7 \pm 17.8$ & $116 \pm 16.7$ \\
\hline Height (cm) & $163.9 \pm 9.07$ & $162.9 \pm 7.7$ & $163.1 \pm 8.2$ & $161.2 \pm 9.1$ \\
\hline BMI $\left(\mathrm{kg} / \mathrm{m}^{2}\right)$ & $44.8 \pm 2.8$ & $46.8 \pm 4.6$ & $44.8 \pm 4.7$ & $44.4 \pm 2.8$ \\
\hline Ideal body mass $(\mathrm{kg})^{\mathrm{a}}$ & $60.9 \pm 6.1$ & $59.9 \pm 4.5$ & $60.6 \pm 4.9$ & $60.6 \pm 4.3$ \\
\hline \multicolumn{5}{|c|}{$\begin{array}{l}\mathrm{F}=\text { female; } \mathrm{M}=\text { male; } \mathrm{BMI}=\text { body mass index; avalue based on the Metropolitan Life } \\
\text { Foundation (1983); Gpre=group treated with positive pressure before surgery } \\
\text { Gpos=group treated with positive pressure after surgery; Gintra=group treated } \\
\text { with positive pressure during the surgical procedure; Gcontrol=group treated } \\
\text { with conventional physiotherapy. }\end{array}$} \\
\hline
\end{tabular}

There was a statistically significant difference for ERV and for the percentage of predicted ERV, in which the groups that received the treatment showed a smaller loss of ERV from the preoperative to postoperative periods (Table 2).

The analysis of the preoperative chest radiographies showed no abnormalities for any of the patients. However, in the postoperative radiographies, there was a prevalence of $25 \%$ atelectasis in the control group, $11.1 \%$ for Gintra, $10 \%$ for Gpre and 0\% for Gpos (Figure 2). There was no significant difference in diaphragmatic mobility between the groups (Table 3).

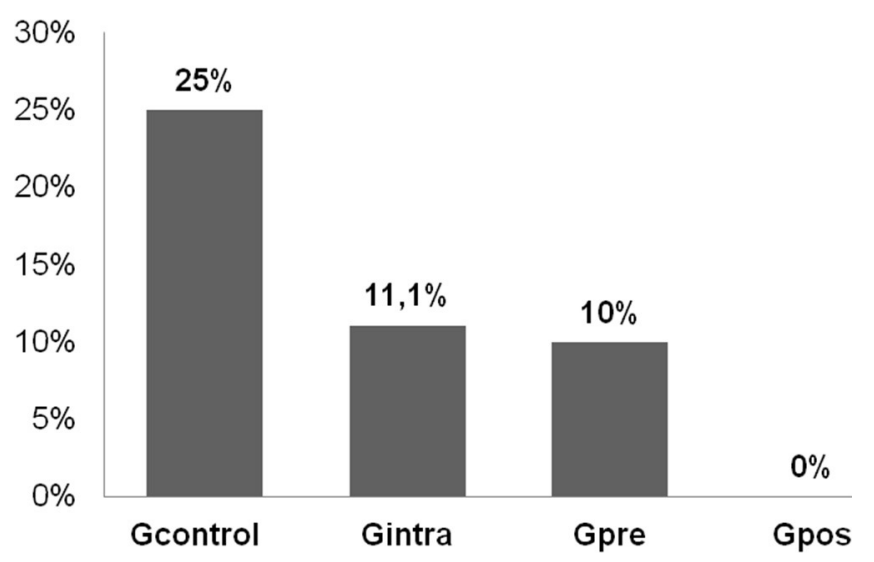

FIGURE 2 - Prevalence of atelectasis in the respective groups

TABLE 3 - Diaphragmatic mobility $(\mathrm{cm})$ in the radiological images obtained preoperatively and postoperatively, presented as median ( $1^{\text {st }}$ quartile $-3^{\text {rd }}$ quartile)

\begin{tabular}{|c|c|c|c|c|c|c|}
\hline & \multicolumn{2}{|c}{ Right dome mobility (cm) } & \multicolumn{2}{c|}{ Left dome mobility (cm) } \\
\hline & Pre & Pos & p-valuea & Pre & Pos & p-valuea \\
\hline Gpre & $4.1(3.8-5.0)$ & $2.2(1.9-3.2)$ & & $4.0(3.5-5.2)$ & $2.5(2.0-3.3)$ & \\
Gpos & $3.9(2.6-5.5)$ & $2.4(1,9-3.0)$ & & $4.3(3.2-5.5)$ & $2.4(2.0-3.1)$ & \\
\hline Gintra & $4.0(2.3-5.0)$ & $3.1(2.5-3.1)$ & 0.71 & $4.2(3.1-5.5)$ & $3.1(2.4-3.4)$ & 0 \\
\hline Gcontrol & $3.3(2.2-4.4)$ & $2.9(1.3-3.0)$ & & $4.3(3.1-6.7)$ & $2.1(0.6-3.5)^{\star}$ & \\
\hline
\end{tabular}

Gpre=group treated with positive pressure before surgery; Gpos=group treated with positive pressure after surgery; Gintra=group treated with positive pressure during the surgical procedure; Gcontrol=group treated with conventional physiotherapy; *statistically significant difference intragroup; ap-value of comparison between groups.

TABLE 2 - Spirometric values for each group before and after treatment, expressed as median, $1^{\text {st }}$ quartile and $3^{\text {rd }}$ quartile

\begin{tabular}{|c|c|c|c|c|c|c|c|c|c|}
\hline & & \multicolumn{2}{|c|}{ Gpre } & \multicolumn{2}{|c|}{ Gpos } & \multicolumn{2}{|c|}{ Gintra } & \multicolumn{2}{|c|}{ Gcontrol } \\
\hline & & Pre & Pos & Pre & Pos & Pre & Pos & Pre & Pos \\
\hline \multirow{3}{*}{ SVC (L) } & $1^{\text {st }}$ quartile & 2.81 & 2.23 & 2.71 & 2.26 & 2.97 & 1.76 & 2.50 & 1.72 \\
\hline & Median & 3.25 & $2.52^{\star}$ & 3.30 & $2.83^{*}$ & 3.58 & $2.48^{*}$ & 3.39 & $2.19^{*}$ \\
\hline & $3^{\text {rd }}$ quartile & 3.55 & 2.85 & 4.04 & 3.45 & 4.31 & 2.84 & 3.69 & 2.83 \\
\hline \multirow{3}{*}{ SVC (\%pred) } & $1^{\text {st }}$ quartile & 89.95 & 61.12 & 78.62 & 59.72 & 87.9 & 47.75 & 85.95 & 54.02 \\
\hline & Median & 91.15 & $72.6^{*}$ & 97.85 & $82.6^{*}$ & 100.75 & $73.2^{*}$ & 91.15 & $70.6^{*}$ \\
\hline & $3^{\text {rd }}$ quartile & 98.22 & 83.2 & 102.75 & 95.77 & 113.0 & 82.62 & 101.15 & 75.57 \\
\hline \multirow{3}{*}{ ERV (L) } & $1^{\text {st }}$ quartile & 0.17 & 0.14 & 0.24 & 0.24 & 0.15 & 0.32 & 0.25 & 0.06 \\
\hline & Median & 0.38 & $0.29^{\circ}$ & 0.40 & $0.40^{\circ}$ & 0.56 & $0.37^{\infty}$ & 0.54 & $0.14^{*}$ \\
\hline & $3^{\text {rd }}$ quartile & 0.52 & 0.51 & 0.58 & 0.76 & 0.70 & 0.50 & 1.09 & 0.31 \\
\hline \multirow{3}{*}{ ERV (\%pred) } & $1^{\text {st }}$ quartile & 15.2 & 16.32 & 21.92 & 23.95 & 16.2 & 28.12 & 25.4 & 5.77 \\
\hline & Median & 33.4 & $30.0^{\infty}$ & 34.25 & $31.7^{\infty}$ & 47.2 & $30.55^{\circ}$ & 45.4 & $13.7^{*}$ \\
\hline & $3^{\text {rd }}$ quartile & 44.5 & 37.6 & 48.12 & 67.92 & 54.1 & 45.27 & 83.5 & 28.25 \\
\hline \multirow{3}{*}{ IRV (L) } & $1^{\text {st }}$ quartile & 2.05 & 1.38 & 1.58 & 1.33 & 1.94 & 0.94 & 1.72 & 1.27 \\
\hline & Median & 2.34 & $1.72^{\star}$ & 2.23 & $1.61^{*}$ & 2.21 & $1.50 *$ & 2.14 & 1.53 \\
\hline & $3^{\text {rd }}$ quartile & 2.43 & 1.86 & 2.64 & 2.20 & 2.83 & 1.89 & 2.42 & 2.03 \\
\hline \multirow{3}{*}{ FVC (L) } & $1^{\text {st }}$ quartile & 2.83 & 2.35 & 2.91 & 2.38 & 3.15 & 1.85 & 2.38 & 1.71 \\
\hline & Median & 3.31 & $2.62^{*}$ & 3.55 & $2.90^{*}$ & 3.42 & $2.53^{*}$ & 3.36 & $2.40^{*}$ \\
\hline & $3^{\text {rd }}$ quartile & 3.66 & 2.95 & 4.34 & 3.55 & 4.27 & 3.02 & 3.89 & 2.75 \\
\hline \multirow{3}{*}{ FVC (\%pred) } & $1^{\text {st }}$ quartile & 89.65 & 67.45 & 83.7 & 64.42 & 94.9 & 52.12 & 88.5 & 58.47 \\
\hline & Median & 93.35 & $75.3^{*}$ & 101.15 & $85.15^{\star}$ & 101.5 & $75.3^{*}$ & 92.0 & $68.3^{*}$ \\
\hline & $3^{\text {rd }}$ quartile & 96.10 & 82.27 & 111.1 & 95.95 & 108.52 & 81.9 & 102.5 & 78.57 \\
\hline
\end{tabular}

SVC=slow vital capacity; ERV=expiratory reserve volume; IRV=inspiratory reserve volume; FVC=forced vital capacity; Gpre=group treated with positive pressure before surgery; Gpos=group treated with positive pressure after surgery; Gintra=group treated with positive pressure during the surgical procedure; Gcontrol=group treated with conventional physiotherapy; ${ }^{*}$ statistically significant difference intragroup; ${ }^{\circ}$ statistically significant difference compared to Gcontrol. 
DISCUSSION

Blouw et al. (2003) found a prevalence of $14 \%$ of respiratory failure in patients with a BMI above $43 \mathrm{~kg} / \mathrm{m}^{2}$ after bariatric surgery. Studies such as this highlight the need for prophylactic interventions to prevent respiratory complications in patients undergoing bariatric surgery.

The results of the study with ERV were similar to those of Barbalho-Moulim et al. (2009) in which a comparison was made between incentive spirometry and the use of expiratory positive airway pressure. They concluded that incentive spirometry increased the inspiratory volumes and expiratory positive airway pressure prevented early airway collapse. So, since the BiPAP mode had two pressure levels both in the inspiratory phase and in the expiratory phase, it can be supposed there is a combination of the benefits provided by both incentive spirometry and expiratory positive airway pressure.

The improvement in ERV found in Gintra can be explained by the fact that the induction of anesthesia and manipulation of the abdominal cavity during surgery resulted in cephalic displacement of the diaphragm, reducing the functional residual capacity (Levi et al., 2003). With the addition of PEEP at $10 \mathrm{~cm} \mathrm{H}_{2} \mathrm{O}$, the collapsed areas could be expanded, and remain as such in the postoperative period. Expanded lungs associated with conventional physiotherapy can generate an increase in alveolar ventilation and consequently an increase in ERV.

Concerning the other spirometric variables, there is often a decrease in lung function after surgical procedures, since there are numerous factors that influence the performance of the maneuvers, such as pain and the fear to take a deep breath (Smith et al., 2000). In this study care was taken in the orientation and the use of analgesia in the procedure, to minimize the interference of pain in the measurements. In fact, major changes in lung function were not expected.

The respiratory therapy in patients undergoing bariatric surgery also aims to prevent atelectasis, often found in these patients, and the usual cause of respiratory failure and postoperative complications (Eichenberger et al., 2002; Blouw et al., 2003).

Some studies have reported that atelectasis arises at the time of induction of anesthesia in all patients, but only persists in the postoperative period in obese patients (Eichenberger et al., 2002). Thus one of the hypotheses of this study was that the use of PEEP at $10 \mathrm{cmH}_{2} \mathrm{O}$ throughout the surgical procedure would be sufficient to reduce the prevalence of atelectasis in these patients (Woodring et al., 1996; Sood 2009). In fact, when compared to the control group, PEEP decreased the prevalence of postoperative atelectasis, but the most effective treatment for this purpose was observed with the use of positive pressure immediately after surgery (Gpos), in which case the incidence of atelectasis was null.

In the present study, the volunteers in the Gpos group were treated with positive pressure in the postanesthesia recovery room after extubation. The favorable results obtained with the use of this equipment may have been due to the correction of hypoventilation in the obese patients. One of the characteristics of the morbidly obese is alveolar hypoventilation, due to the accumulation of abdominal fat and also to changes in the ventilation mechanics (Shah et al., 2009; Chau et al., 2012), and after being under a general anesthetic, the hypoventilation may be aggravated in the early hours in the recovery room (Moore et al., 2011; Schumann 2011). Thus the positive pressure pressurizes the airways in the first hours after anesthesia and improves alveolar ventilation in possibly collapsed areas after the surgical procedure, preventing postoperative atelectasis (Schumann 2011).

Several authors have demonstrated beneficial effects of using noninvasive ventilation during the postoperative stage of bariatric surgery (Ricksten et al., 1986; El-Solh et al., 2006; Yee et al., 2006; Gaszynski et al., 2007; Neligan et al., 2009). In this study, a group treated with noninvasive positive pressure in the preoperative stage was included, with the hypothesis that previously expanded lungs could influence the surgical procedure and general anesthesia by reducing the prevalence of atelectasis and postoperative complications. In fact, the use of positive pressure for one hour immediately before the surgical procedure was able to reduce the prevalence of atelectasis and improve ERV in the postoperative stage, resembling the benefits of using PEEP during surgery and non-invasive positive pressure in the postoperative stage.

Other studies have shown the beneficial effects of using the alveolar recruitment maneuver in these patients (Souza et al., 2009; Remístico et al., 2011) using PEEP levels up to $30 \mathrm{cmH}_{2} \mathrm{O}$. But there is still controversy in clinical practice with respect to the use of values greater than $10 \mathrm{cmH}_{2} \mathrm{O}$ for obese individuals, since they can cause significant hemodynamic changes (García et al., 2012) or pulmonary overdistension (Rama-Maceiras 2010), and in addition can decrease the venous return by increasing intrathoracic pressure (Luecke et al., 2005), which can generate venous stasis, especially in the lower limbs, increasing the risk of deep vein thrombosis.

However, in the study presented here, better results were obtained when using higher levels of PEEP (10 $\mathrm{cmH}_{2} \mathrm{O}$ ), when compared to the use of lower values in the control group $\left(5 \mathrm{cmH}_{2} \mathrm{O}\right)$. Coussa et al. (2004) also ventilated the patients with PEEP at $10 \mathrm{~cm} \mathrm{H}_{2} \mathrm{O}$ during surgery, and observed the prevention of intraoperative atelectasis. However, there was no follow-up of these patients in the postoperative period. The present study confirmed that high levels of PEEP during surgery can maintain lung expansion for up to 48 hours after extubation, as confirmed by the decreased prevalence of atelectasis shown on the chest radiographies on the second day after surgery.

Finally, in relation to diaphragmatic mobility, this was not modified by the treatments, with no differences between the groups. Barbalho-Moulim et al. (2009) also evaluated diaphragmatic mobility by radiological imaging, before and after bariatric surgery, and showed the least loss of mobility in the group treated with incentive spirometry versus expiratory positive airway pressure, justified by the fact that incentive spirometry works with deep breaths, requesting the use of the diaphragmatic muscles. In the present study, there was a loss of diaphragmatic mobility in all the groups, but no difference between them. This can be explained by the fact that the control group carried out incentive spirometry postoperatively as part of the hospital routine, which helped ensure diaphragmatic mobility.

\section{CONCLUSION}

The application of positive pressure at any time contributes to a reduction in the loss of expiratory reserve volume. However, when applied postoperatively, decreases the incidence of atelectasis. There is no interference of positive pressure on the diaphragmatic mobility. Therefore, the optimal time of application of positive pressure is in the postoperative period, immediately after extubation, because it reduces the incidence of atelectasis and there is reduction of loss of expiratory reserve volume. 


\section{ACKNOWLEDGEMENTS}

To Coordenação de Aperfeiçoamento de Pessoal de Nível Superior (CAPES/PROSUP) and Lumiar Saúde - Terapia Respiratória.

\section{REFERENCES}

1. ATS/ERS Task Force. Standardisation of lung function testing Standardisation of Spirometry. Eur Respir J 2005;26(2):319-38.

2. Barbalho-Moulim MC, Miguel GPS, Forti EMP, César MC, Azevedo JLMC, Costa D. Silicone-ring Roux-en-y gastric bypass in the treatment of obesity: effects of laparoscopic versus laparotomic surgery on respiration. Obes Surg 2011;21(2):194-9.

3. Barbalho-Moulim MC, Miguel GPS, Forti EMP, Costa D. Comparação entre inspirometria de incentivoe pressão positiva expiratória na função pulmonar após cirurgia bariátrica. Fisioter Pesqui 2009;16(2):166-72.

4. Blouw EL, Rudolph AD, Narr BJ, Sarr MG. The frequency of respiratory failure in patients with morbid obesity urdergoing gastric bypass. AANA J 2003;71(1):45-50.

5. Chau EHL, LamD, Wong J,MokhlesiB,Chung F.Obesity hypoventilation syndrome: a review of epidemiology, pathophysiology, and perioperative considerations. Anesthesiology 2012;117(1):188-205.

6. Chung F, Mezei G, Tong D. Pre-existing medical conditions as predictors of adverse events in day-case surgery. BrJ Anaesth 1999;83(2):262-70.

7. Coussa M, Proietti S, Schnyder P, Frascarolo P, Suter M, Spahn DR, et al. Prevention of atelectasis formation during the induction of general anesthesia in morbidly obese patients. Anesth Analg 2004;98(5):1491-5.

8. Downie WW, Leatham PA, Rhind VM, Wright V, Branco JA, Anderson JA. Studies withpain rating scales. Ann Rheum Dis 1978;37(4):378-81.

9. Duggan M, Kavanagh BP. Pulmonary atelectasis: a pathogenic perioperative entity. Anesthesiology 2005;102(4):838-54.

10. Eichenberger AS, Proietti S, Wicky S, Frascarolo P, Suter M, Spahn DR, et al. Morbid obesity and postoperative pulmonary atelectasis: an underestimated problem. Anesth Analg 2002;95(6):1788-92.

11. El-Solh AA, Aquilina A, Pineda L, Dhanvantri V, Grant B, Bouquin P. Noninvasive ventilation for prevention of post-extubation respiratory failure in obese patients. Eur Respir J 2006;28(3):588-95.

12. GarcíaM,CanoAG, RomeroMG,MonrovéJCD.Cambiosrespiratoriosy hemodinámicos durante una maniobra de reclutamiento pulmonar mediante incrementos y decrementos progresivos de PEEP. Med Intensiva 2012;36(2):77-88.

13. Gaszynski T, Tokarz A, Piotrowski D, Machala W. Boussignac CPAP in the Postoperative Period in Morbidly Obese Patients. Obes Surg 2007;17(4):452-6.

14. Lawrence VA, Cornell JE, Smetana GW. Strategies to reduce postoperative pulmonary complications after noncardiothoracic surgery: systematic review for the American College of Physicians. Ann Intern Med 2006;144(8):596-608.

15. Levi D, Goodman ER, Patel M, Savransky Y. Critical care of the obese and bariatric surgical patient. Crit Care Clin 2003;19(1):11-32.
16. Luecke T, Pelosi P. Clinical review: Positive end-expiratory pressure and cardiac output. CritCare 2005;9(6):607-21.

17. Lundquist H, Hedenstierna G, Strandberg A, Tokics L, Brismar B. $\mathrm{CT}$ assessment of dependent lung densities in manduring general anaesthesia. Acta Radiol 1995;36(6):626-32.

18. Metropolitan Life Foundation: Metropolitan height and weight tables. Stat Bull 1983;64(1):2-9.

19. Moore CE, Forrest $\mathrm{M}$, Ammori B. Anaesthesia for obesity surgery. Anaesth Intensive Care Med 2011;12(7):280-2

20. Neligan PJ, Malhotra G, Fraser M, Williams N, Greenblatt EP, Cereda $\mathrm{M}$, et al. Continuous positive airway pressure via the boussignac system immediately after extubation improves lung function in morbidly obese patients with obstructive sleep apnea undergoing laparoscopic bariatric surgery. Anesthesiology 2009;110(4):878-84.

21. Pereira CAC, Barreto SP, Simões JG, et al. Valores de referência para espirometria em uma amostra da população brasileira adulta. J Pneumol 1992;18(1):10-22.

22. Pereira CAC. Directives for pulmonary function tests. J Pneumol 2002;28(3):1-82.

23. Perilli. V, Sollazzi L, Bozza P, Modesti C, Chierichini A, Tacchino RA, et al. The effects of the reverse trendelenburg position on respiratory mechanics and blood gases in morbidly obese patients during bariatric surgery. Anesth Analg 2000;91(6):1520-5.

24. Rama-MaceirasP.Peri-operativeatelectasisand alveolarrecruitment manoeuvres. Arch Bronconeumol 2010;46(6):317-24.

25. Remístico PPJ, Araújo S, Figueiredo LC, Aquim EE, Gomes LM, Sombrio ML, et al. Impact of alveolar recruitment maneuver in the postoperative period of videolaparoscopic bariatric surgery. Rev Bras Anestesiol 2011;61(2):163-8.

26. Ricksten SE, Bengtsson A, Soderberg C, Thorden M, Kvist H. Effects of periodic positive airway pressure by mask on postoperative pulmonary function. Chest 1986;89(6):774-81.

27. Rose K, Cohen MM, Wigglesworth DF, DeBoer DP. Critical respiratory events in the post anesthesia care unit: patient, surgical, and anesthetic factors. Anesthesiology 1994;81(2):410-8.

28. Schumann R. Anaesthesia for bariatric surgery. Best Pract Res Clin Anaesthesiol 2011;25(1):83-93.

29. Scott J, Huskisson EC: Graphic representation of pain. Pain. 1976;2(2):175-84

30. Shah N, Roux F. The relationship of obesity and obstructive sleep apnea. Clin Chest Med 2009;30(3):455-65.

31. Smith $\mathrm{MCL}$, Ellis ER. Is retained mucus a risk factor for the development of postoperative atelectasis and pneumonia? Implications for the physiotherapist. Physiother Theory Pract 2000;16(2):69-80.

32. Sood A. Altered resting and exercise respiratory physiology in obesity. Clin Chest Med 2009;30(3):445-54.

33. Souza AP, Buschpigel M, Mathias LAST, Malheiros CA, Alves VLS Análise dos efeitos da manobra de recrutamento alveolar na oxigenação sanguínea durante procedimento bariátrico. Rev Bras Anestesiol 2009;59(2):177-86.

34. Woodring JH, Reed JC. Types and mechanisms of pulmonary atelectasis. J Thorac Imaging 1996;11(2):92-108

35. Yee BJ, Cheung J, Phipps P, Banerjee D, Piper AJ, Grunstein RR. Treatment of obesity hypoventilation syndrome and serum leptin. Respiration 2006;73(2):209-12. 